\title{
Seleção de Parâmetros Através do Método Taguchi para Soldagem de Revestimento com Ligas de Níquel pelo Processo MIG/MAG
}

\author{
(Using the Taguchi method to select welding parameters for Weld Overlay with nickel alloy through the GMAW process)
}

\author{
Antonio Rodolfo Paulino Pessoa ${ }^{1}$, Hélio Cordeiro de Miranda ${ }^{1}$, Jesualdo Pereira Farias ${ }^{1}$, Willys Machado Aguiar ${ }^{2}$, \\ Francisco de Assis Filho ${ }^{3}$. \\ ${ }^{1}$ Universidade Federal do Ceará, Departamento de Engenharia Metalúrgica e de Materiais, Fortaleza, Ceará, Brasil, \\ antrodolfo.pessoa@bol.com.br, hmiranda@ufc.brejpfarias@ufc.br. \\ ${ }^{2}$ Instituto Federal de Educação, Ciência e Tecnologia do Ceará, Departamento de Indústria, Fortaleza, Ceará, Brasil, \\ willys@ifce.edu.br. \\ ${ }^{3}$ Universidade Federal do Ceará, Departamento de Engenharia Mecânica e de Produção, Fortaleza, Ceará, Brasil, \\ assisfilho@yahoo.com.br.
}

\begin{abstract}
Resumo
Neste trabalho utilizou-se o método Taguchi (planejamento Robusto de experimentos), para cumprir com um reduzido número de ensaios, dois objetivos: obter a influência dos fatores de controle sobre as variáveis respostas e determinar as condições ideais para aplicação das ligas de níquel nas soldagens de revestimentos através do processo MIG/MAG com transferência metálica por curto-circuito. Foram escolhidos seis fatores de controle com três níveis cada: Tensão de referência, Velocidade de soldagem, Tipo de tecimento, Técnica da tocha, Gás de proteção e o Material de adição. Por sua vez as variáveis respostas escolhidas foram: Diluição (D) e Razão entre o reforço e a largura $(R / L)$. As soldagens foram realizadas na posição plana por simples deposição sobre chapas de aço ASTM 516 Gr60 com dimensões de $200 \times 50 \times 12,7 \mathrm{~mm}$. O uso do tecimento proporcionou cordões com baixos valores da razão $R / L$ e obteve valores bastante baixos de diluição chegando à ordem de 5\%. A combinação dos níveis dos fatores de controle apontados como ótimos pelo método Taguchi resultaram em valores para as variáveis repostas consideradas adequadas para a soldagem de revestimento.
\end{abstract}

Palavras-chave: Ligas de níquel; Método Taguchi; MIG/MAG e Curto-circuito.

Abstract: In this work aim the Taguchi method (Robust design of experiments) was chosen to achieve with a limited number of tests two objectives: the first was to the influence of the control factors (welding parameters) on quality characteristics (weld bead geometry) and the second was to determine optimal conditions for weld overlay with nickel alloy through the GMAW process in a short circuiting transfer mode. Six control factors were employed with three levels each: Reference voltage, Welding speed, Arc oscillation, welding gun orientation (Perpendicular, forehand and backhand), Shielding gas and filler metal. Already the employed quality characteristics were: Percent dilution $(D)$ and the ration between reinforcement and bead width $(R / L)$. The weldings were accomplished using a bead on plate (BOP) technique, flat position, in steel ASTM $516 \mathrm{Gr} 60$ with dimensions of $200 \times 50 \times 12,7 \mathrm{~mm}$. The results showed that the use of arc oscillation promote weld bead with low values of the ratio $R / L$ and obtain low dilution's values arriving to the order of $5 \%$. The combination of levels of control factors identified as optimal by the Taguchi method obtained values for the variables considered suitable for weld overlay.

Key-words: Nickel alloys; Robust Design; GMAW and Short circuiting.

\section{Introdução}

A indústria do petróleo e gás natural no Brasil vem buscando constantemente alternativas no sentido de reduzir os custos ao minimizar os desgastes causados pela corrosão em suas unidades de refino e processamento de petróleo, o que se deve ao elevado índice de acidez encontrado nos petróleo pesados processados nestas unidades. Recentemente as ligas de níquel vêm sendo

(Recebido em 05/04/2010; Texto final em 26/11/2010). Artigo originalmente publicado no CONSOLDA 2009, Piracicaba, SP, Outubro de 2009. sugeridas como uma das alternativas para adequar ou substituir componentes metálicos que compõem os equipamentos das unidades de produção e refino. Apesar das ligas de níquel constituírem uma alternativa viável para substituir ou adequar os equipamentos empregados nestas unidades, o elevado custo de fabricação de equipamentos ou de componentes maciços constituídos por estas ligas fazem com que os mesmos sejam normalmente construídos com materiais menos nobres, como aços C-Mn e baixa liga e posteriormente revestidos com materiais de excelente resistência à corrosão.

Contudo, faz-se necessário um estudo sistemático do processo para uma aplicação apropriada destas ligas como revestimentos metálicos de elevada resistência à corrosão e a oxidação. Assim 
os objetivos deste trabalho são avaliar, utilizando o método Taguchi, a influência de algumas das variáveis de soldagem (denominadas neste trabalho de "fatores de controle") sobre as características dos cordões de solda (denominadas de "variáveis respostas") e determinar as condições ideais para aplicação por soldagem de revestimentos. Foi empregado o processo MIG/ MAG operando em modo de tensão constante e transferência metálica por curto-circuito, para deposição dos revestimentos com as ligas UNS N06625 (Inconel 625), UNS N10276 (Hastelloy C-276) e UNS N06686 (Inconel 686) sobre um substrato de aço C-Mn.

\section{Matérias e Métodos}

\subsection{Materiais de consumo}

Neste trabalho foram utilizadas como material de base, placas de aço ASTM A516 grau 60 com dimensões de 200 x $50 \times 12,7 \mathrm{~mm}$ e como metais de adição foram empregados três arames eletrodo com 1,2 mm de diâmetro: AWS ERNiCrMo-3, AWS ERNiCrMo-4 e o AWS ERNiCrMo-14. Nos ensaios também foram utilizados três gases de proteção: Argônio Puro (100\% Ar), uma mistura gasosa contendo $70 \%$ de argônio e 30\% de Hélio $(70 \% \mathrm{Ar}+30 \% \mathrm{He})$ e uma mistura gasosa contendo $99,97 \%$ de argônio e 0,03 \% de óxido nítrico $(99,97 \% \mathrm{Ar}+$ $0,03 \%$ NO).

\subsection{Equipamentos e acessórios}

Os equipamentos utilizados na realização das soldagens foram

- Robô industrial para deslocamento automático da tocha de soldagem

- Uma fonte de soldagem eletrônica multiprocesso

- Sistema de aquisição dos sinais de tensão e corrente operando em frequiência de $9600 \mathrm{~Hz}$

\subsection{Metodologia}

O trabalho foi realizado através de seis etapas básicas:

- Seleção dos fatores de controle e seus níveis;

- Seleção das variáveis respostas;

- Escolha da matriz experimental;

- Realização das soldagens;

- Medição das características geométricas para obtenção das variáveis respostas;

- Realização de ensaios de confirmação.

\subsubsection{Planejamento dos experimentos}

As três primeiras etapas citadas acima correspondem ao planejamento dos experimentos, onde optou-se pelo uso do método Taguchi com o intuito de reduzir o número de ensaios necessários caso fosse utilizado o método do fatorial completo. Assim foram escolhidos seis fatores de controle com três níveis cada: Tensão de referência $(\mathrm{Ur}=20,22,24 \mathrm{~V})$, Velocidade soldagem ( $\mathrm{Vs}=0,2,0,3$ e 0,4 $\mathrm{m} / \mathrm{min}$ ), Tipo de tecimento (Sem tecimento ou ST, duplo oito ou D8 e Tecimento triangular ou TT mostrados na Figura 1), Técnica da tocha (normal, empurrando e puxando mostrados na Figura 2), Gás de proteção (100\%Ar, $70 \% \mathrm{Ar}+30 \% \mathrm{He}$ e $99,97 \% \mathrm{Ar}+0,03 \% \mathrm{NO})$ e o Material de adição (Liga= ERNiCrMo-3 ou 625, ERNiCrMo-14 ou 686 e ERNiCrMo-4 ou C-276).

(a)

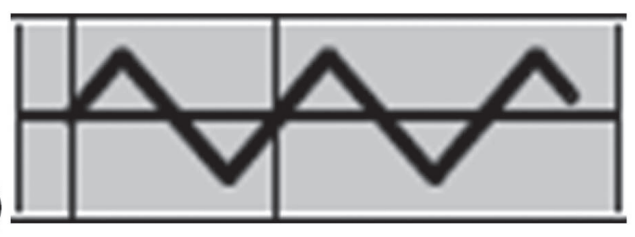

(b)

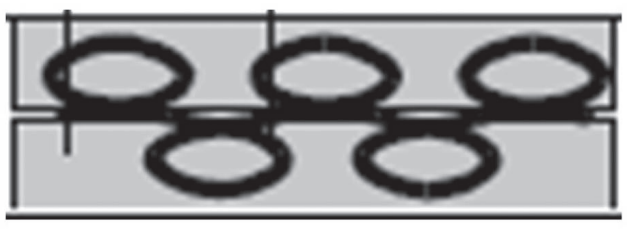

Figura 1 - Tipo de tecimento: (a)Tecimento triangular e (b) Tecimento em duplo oito.

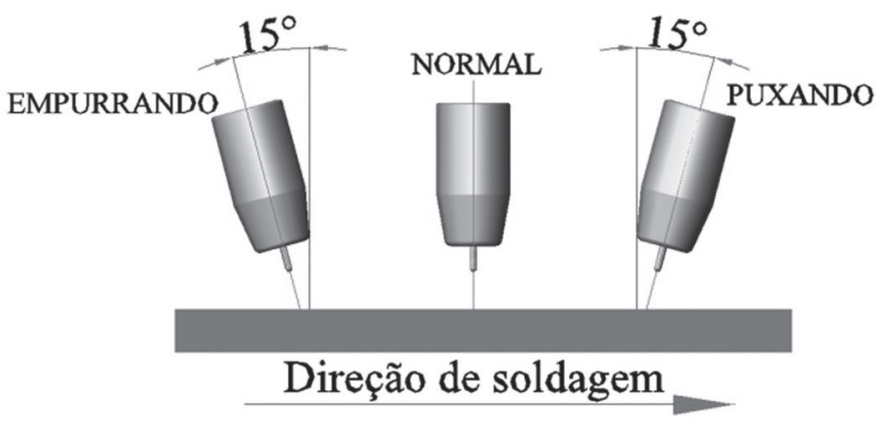

Figura 2 - Posições da tocha.

Os fatores de controle foram divididos pelo método Taguchi em duas matrizes L9, resultando num total de 18 ensaios, cerca de 1/9 dos ensaios necessários em um fatorial completo (162 ensaios). A Tabela 1 e a Tabela 2 mostram as combinações dos níveis dos fatores de controle e a sequência de execução dos ensaios. Vale lembrar que, em todos os ensaios relativos à matriz L9-1, utilizou-se o argônio puro como gás de proteção e a liga 625 como material de adição e em todos os ensaios pertencentes à matriz L9-2 foram utilizados a posição empurrando para a técnica da tocha e o uso tecimento triangular.

As variáveis respostas escolhidas como critérios de qualidade foram: A diluição (D), a razão entre o reforço e a largura (R/L). A escolha da diluição como critério de qualidade se deve ao fato de que uma das aplicações das soldagens de revestimento é a proteção contra corrosão, por isso é importante controlar a participação do metal de base na composição do metal de solda, 
Tabela 1 - Ensaios realizados com a matriz L9-

\begin{tabular}{|c|c|c|c|c|}
\hline Ensaio & Ur (V) & Técnica da Tocha & Tipo de tecimento & Vs (m/min) \\
\hline R01 & $1(20)$ & 1 (Normal) & 1 (Sem Tecimento) & $1(0,2)$ \\
\hline R02 & $1(20)$ & 2 (Empurrando) & 2 (Tec.Triangular) & $2(0,3)$ \\
\hline R03 & $1(20)$ & 3 (Puxando) & 3 (Duplo oito ) & $3(0,4)$ \\
\hline R04 & $2(22)$ & 1 (Normal) & 2 (Tec.Triangular) & $3(0,4)$ \\
\hline R05 & $2(22)$ & 2 (Empurrando) & 3 (Duplo oito ) & $1(0,2)$ \\
\hline R06 & $2(22)$ & 3 (Puxando) & 1 (Sem Tecimento) & $2(0,3)$ \\
\hline R07 & $3(24)$ & 1 (Normal) & 3 (Duplo oito ) & $2(0,3)$ \\
\hline R08 & $3(24)$ & 2 (Empurrando) & 1 (Sem Tecimento) & $3(0,4)$ \\
\hline R09 & $3(24)$ & 3 (Puxando) & 2 (Tec.Triangular) & $1(0,2)$ \\
\hline
\end{tabular}

Tabela 2 - Ensaios realizados com a matriz L9-2

\begin{tabular}{|c|c|c|c|c|}
\hline Ensaio & Liga & Gás de proteção & Vs (m/min) & Ur (V) \\
\hline R10 & $1(625)$ & $1(100 \% \mathrm{Ar})$ & $1(0,2)$ & $1(20)$ \\
\hline R11 & $1(625)$ & $2(70 \% \mathrm{Ar}+30 \% \mathrm{He})$ & $2(0,3)$ & $2(22)$ \\
\hline R12 & $1(625)$ & $3(99,97 \% \mathrm{Ar}+0,03 \% \mathrm{NO})$ & $3(0,4)$ & $3(24)$ \\
\hline R13 & $2(686)$ & $1(100 \% \mathrm{Ar})$ & $2(0,3)$ & $3(24)$ \\
\hline R14 & $2(686)$ & $2(70 \% \mathrm{Ar}+30 \% \mathrm{He})$ & $3(0,4)$ & $1(20)$ \\
\hline R15 & $2(686)$ & $3(99,97 \% \mathrm{Ar}+0,03 \% \mathrm{NO})$ & $1(0,2)$ & $2(22)$ \\
\hline R16 & $3(\mathrm{C}-276)$ & $1(100 \% \mathrm{Ar})$ & $3(0,4)$ & $2(22)$ \\
\hline R17 & $3(\mathrm{C}-276)$ & $2(70 \% \mathrm{Ar}+30 \% \mathrm{He})$ & $1(0,2)$ & $3(24)$ \\
\hline R18 & $3(\mathrm{C}-276)$ & $3(99,97 \% \mathrm{Ar}+0,03 \% \mathrm{NO})$ & $2(0,3)$ & $1(20)$ \\
\hline
\end{tabular}

tendo em vista que uma diluição elevada prejudica a resistência à corrosão do revestimento, o que torna este critério do tipo menor é melhor. Já a razão R/L tem sua escolha justificada pelo fato desta variável representar o grau de convexidade do cordão de solda, onde altos valores de $\mathrm{R} / \mathrm{L}$ proporcionam concentrações de tensão no pé do cordão de solda e favorecem a ocorrência de defeitos como a falta de fusão indesejáveis na soldagem de revestimento, por isso este critério é do tipo menor melhor.

\subsubsection{Realização das soldagens}

As soldagens foram realizadas na posição plana por simples deposição dos arames eletrodos sobre as placas de aço ASTM 516 Gr60. As variáveis mantidas constantes em todos os ensaios foram: a vazão do gás de proteção em $20 \mathrm{~L} / \mathrm{min}$, a velocidade de alimentação em 6,0 m/min e a DBCP (Distância Bico de Contato à Peça) em $20 \mathrm{~mm}$.

\subsubsection{Medição das características geométricas para obtenção das variáveis respostas}

Para a medição das características geométricas (largura, reforço, penetração e diluição) mostradas na Figura 3, foram retiradas duas amostras com $10 \mathrm{~mm}$ de largura. A diluição foi calculada, através da relação entre as áreas adicionada e diluída, conforme a Equação 1.

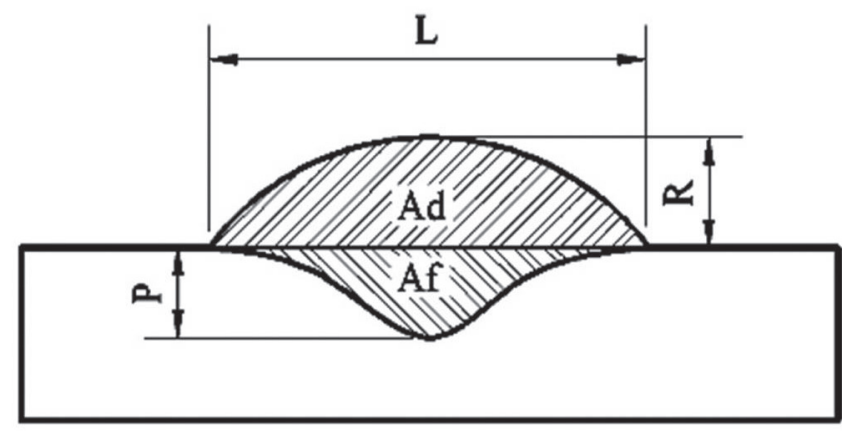

Figura 3 - Perfil geométrico dos cordões de sold

$D=\frac{A f}{(A d+A f)} \times 100(\%)$

Onde:

Ad - Área depositada do cordão (Figura 3)

Af - Área fundida do metal de base (Figura 3)

\subsubsection{Realização dos ensaios de confirmação}

$\mathrm{Na}$ etapa final da análise dos resultados obtidos tanto para matriz L9-1 quanto para matriz L9-2, foram realizados alguns ensaios, chamados de ensaios de confirmação, com o intuito de confirmar a validade da previsão das condições ótimas estabelecidas pelo método Taguchi. 


\section{Resultados e Discussão}

\subsection{Análise de variância no método Taguchi para a matriz L9-1}

A Tabela 3 mostra o resultado de uma análise estatística para as soldagens referentes à matriz L9-1, na qual foi calculada 0 nível de significância " " dos fatores de controle sobre a diluição e a razão R/L. Valores menores que 0,05 (valores sublinhados e em negrito) indicam com uma confiabilidade de $95 \%$, que as variáveis respostas foram afetadas estatisticamente pelos fatores de controle.

Tabela 3 - Nível de significância dos fatores de controle sobre as variáveis respostas.

\begin{tabular}{c|cc|}
\hline \multirow{2}{*}{ Fator de Controle } & \multicolumn{2}{|c}{ Nível de } \\
\cline { 3 - 3 } & Diluição & Razão R/L \\
Ur (V) & $\underline{0,044}$ & $\underline{0,000}$ \\
T.T & 0,103 & $\underline{0,000}$ \\
Tecimento & 0,411 & $\underline{0,000}$ \\
Vs (m/min) & $\underline{0,021}$ & $\underline{0,000}$ \\
\hline
\end{tabular}

Como pode ser visto na Tabela 3 a diluição foi afetada significativamente apenas pela tensão de referência (Ur) e a velocidade de soldagem (Vs). Já a razão R/L sofreu influência significativa de todos os fatores de controle. Vale ressaltar que os fatores de controle que não obtiveram influência significativa sobre as variáveis respostas, não serão comentados nos resultados discutidos a seguir.

\subsection{Previsão da combinação ótima}

Uma das grandes vantagens da condução de experimentos usando o método Taguchi é a previsão da combinação que fornece uma resposta ótima de cada fator de controle, desde que não haja forte interação entre os efeitos dos fatores de controle sobre as respostas. Então, de posse dos resultados obtidos, foram avaliadas as variáveis respostas diluição e razão R/L através de um tratamento estatístico do método Taguchi, onde essas variáveis são um problema de solução do tipo "quanto menor melhor" (Equação 2). Assim as condições necessárias para obter os valores mínimos das variáveis respostas são representadas pelo maior valor de (eta) [1].

$\eta=-10 \log _{10}\left(\frac{1}{n_{i}} \times \sum_{i=1}^{n} y_{i}^{2}\right)$

Onde:

ni $=$ número de repetições num ensaio (número de repetições independente dos níveis de ruído)

yi é a característica da qualidade (resposta observada).

\subsubsection{Análise da variável resposta Diluição (D)}

A Figura 4 mostra a influência dos fatores de controle sobre a diluição, a qual é minimizada para a combinação de fatores de controle nos níveis "1 222 1", ou seja, tensão de referência de $20 \mathrm{~V}$, técnica da tocha empurrando, tecimento triangular e velocidade de soldagem de $0,2 \mathrm{~m} / \mathrm{min}$.

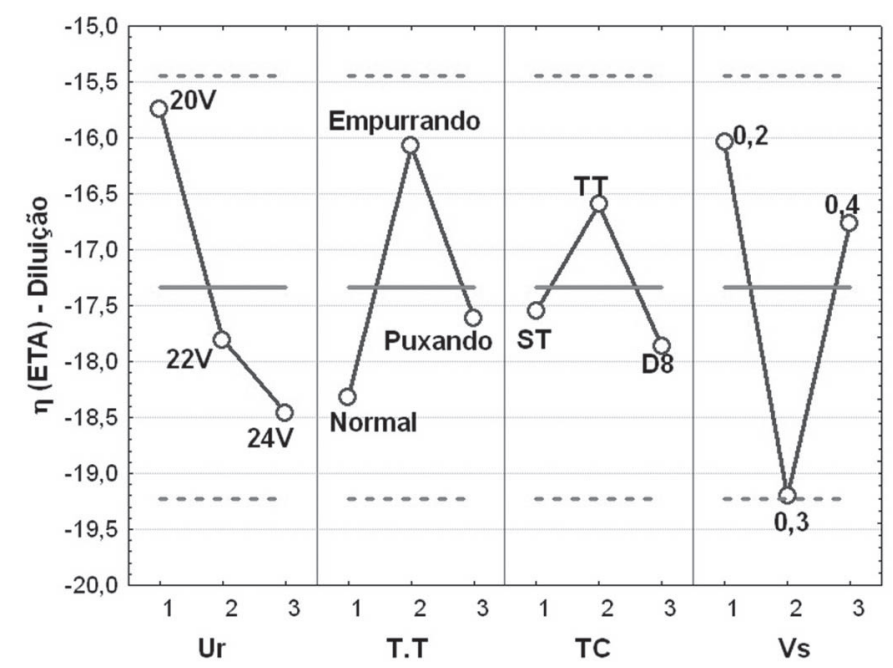

Figura 4 - Influência dos fatores de controle sobre a diluição.

Analisando a Figura 4 e a Tabela 3 é possível extrair algumas informações relevantes do uso do método Taguchi com relação à influência dos fatores de controle sobre a diluição.

A Ur afetou significativamente a diluição e teve o seu Nível $1(20 \mathrm{~V})$ apontado como Nível capaz de minimizá-la. Este resultado indica que, com o aumento da tensão de referência há um aumento nos valores de diluição dos cordões de solda. Isto se deve ao fato que para maiores valores de tensão de referência temse um maior comprimento de arco, que por sua vez proporciona uma coluna de plasma mais ampla em sua extensão, ou seja, com isso o cordão de solda torna-se mais largo e mais achatado proporcionando um pequeno reforço que não atua como uma barreira e não evita que a força do arco haja diretamente sobre a poça de fusão, ocasionando assim um aumento significativo ( $=0,001$ ) da área fundida do metal de base (Figura 5) enquanto a área depositada do cordão de solda (Figura 6) não foi afetada significativamente $(=0,969)$ resultando em maiores valores de diluições $[3,6]$.

A Vs assim como a Ur afetou significativamente a diluição. O menor valor de diluição é obtido pelo Nível $1(0,2 \mathrm{~m} / \mathrm{min})$ deste fator, mas observa-se também que o Nível $3(0,4 \mathrm{~m} /$ min) apresenta um valor bem próximo ao obtido pelo Nível 1. Este fato se deve a relação entre a velocidade de soldagem e a penetração (que resulta na área fundida utilizada no cálculo da diluição) ser influenciada por dois efeitos a serem considerados: o efeito da energia imposta e o efeito do volume da poça de fusão. Assim para a Vs de $0,2 \mathrm{~m} / \mathrm{min}$ o efeito do volume da poça prevalece, ou seja, há uma maior quantidade de material interposto entre o arco e o metal de base tornando mais difícil a transferência de calor para o metal de base e com isso temos uma menor penetração que resulta numa menor diluição. Já com relação a Vs de $0,4 \mathrm{~m} / \mathrm{min}$ o efeito que prevalece é o da energia imposta, ou seja, esta velocidade de soldagem encontrase numa faixa que uma maior velocidade implica em um menor aporte térmico por unidade de comprimento imposto à peca o que resulta em uma menor penetração e consequentemente uma 
menor diluição. E por fim a Vs de $0,3 \mathrm{~m} / \mathrm{min}$ encontra-se numa faixa de velocidade de soldagem que há uma interação entre os dois efeitos, ou seja, a velocidade não é baixa o suficiente para produzir uma sobreposição de poças capaz de evitar a ação direta da força do arco sobre o metal de base e velocidade também não é alta o suficiente para reduzir consideravelmente o aporte térmico imposto ao metal de base, resultando assim na máxima penetração alcançada e por consequiência na maior diluição obtida $[3,5]$.

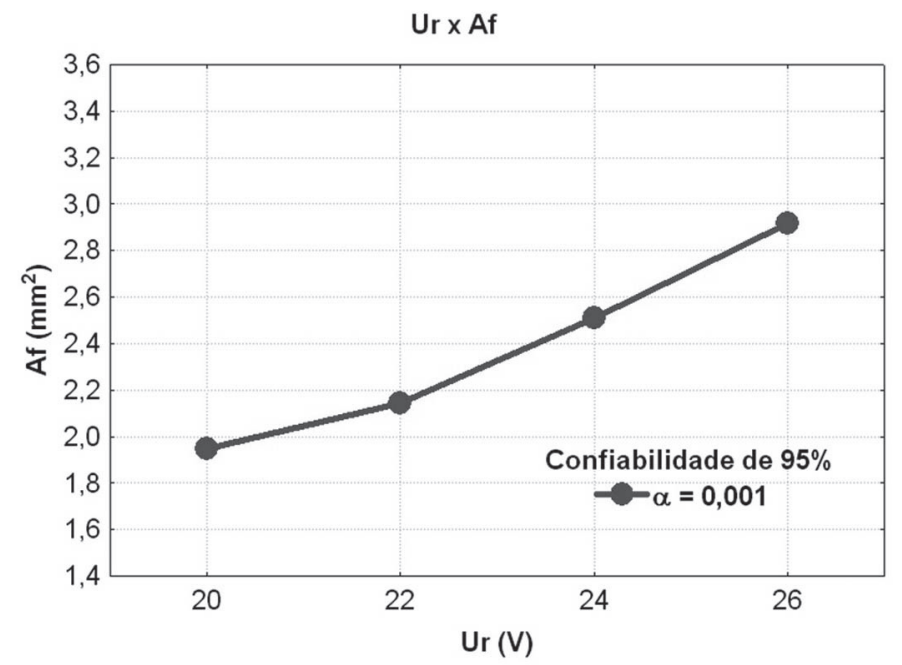

Figura 5 - Influência da tensão de referência sobre a área fundida.

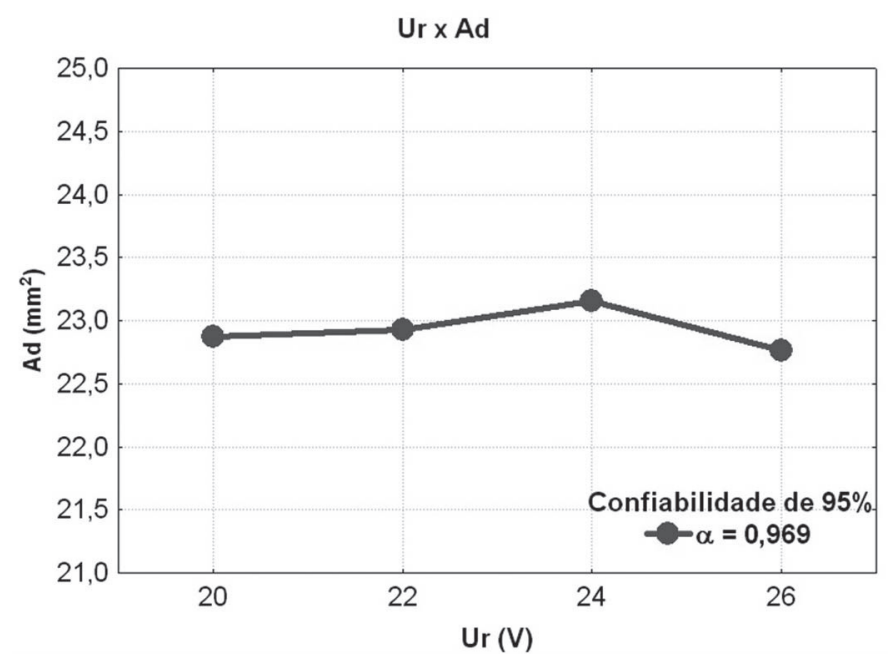

Figura 6 - Influência da tensão de referência sobre a área depositada.

\subsubsection{Análise da variável resposta $R / L$}

A Figura 7 mostra a influência dos fatores de controle sobre a razão $\mathrm{R} / \mathrm{L}$, cujo valor mínimo é alcançado para a combinação de fatores de controle nos níveis "3 22 1", ou seja, tensão de referência de $24 \mathrm{~V}$, técnica da tocha empurrando, tecimento triangular e velocidade de soldagem de $0,2 \mathrm{~m} / \mathrm{min}$.

Analisando de forma conjunta a Figura 7 e a Tabela 3 pode-se obter informações importantes do uso do método Taguchi com relação à influência dos fatores de controle sobre a razão R/L.

A Ur influenciou significativamente, os valores da razão R/L. O Nível 3 (24 V) deste fator é o que apresenta os menores valores para a razão $\mathrm{R} / \mathrm{L}$, o que demonstra que um aumento no valor da Ur resulta numa redução dos valores da razão R/L. Isto se deve ao fato que para maiores valores de tensão de referência tem-se um maior comprimento de arco, que por sua vez proporciona uma coluna de plasma mais larga, ou seja, com isso o cordão de solda torna-se mais largo e mais achatado, resultando num menor reforço e numa menor razão $\mathrm{R} / \mathrm{L}[3,6]$.

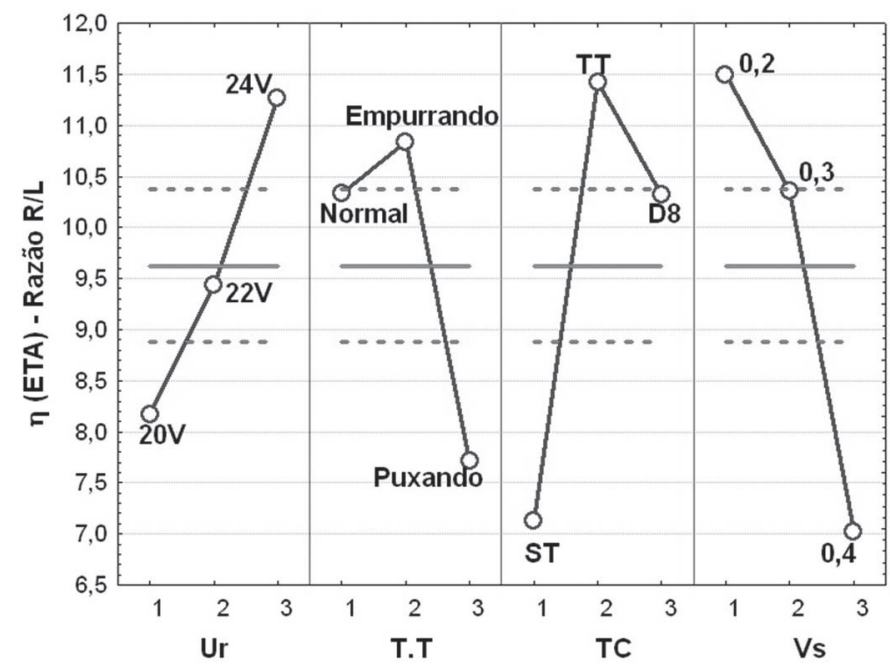

Figura 7 - Influência dos fatores de controle sobre a razão R/L.

A técnica da tocha exerce influência significativa sobre esta variável resposta, e o método Taguchi aponta que, para este fator de controle, o Nível 2 (empurrando) proporciona os menores valores para a razão $\mathrm{R} / \mathrm{L}$. Isso se deve ao fato de que a posição empurrando, conforme explicado anteriormente proporciona de forma geral cordões de solda mais largos, mas não altera o volume de material depositado por unidade de comprimento, o que resulta em menores reforços e com isso há uma redução nos valores da razão $\mathrm{R} / \mathrm{L}$ [2].

$\mathrm{O}$ tecimento influencia significativamente esta variável resposta e o método Taguchi, aponta o Nível 2 (tecimento triangular) como capaz de minimizar a razão $\mathrm{R} / \mathrm{L}$, mas também observa-se que o Nível 3 (duplo oito) proporcionaria valores próximos ao valor obtido pelo Nível 2. Fato que indica que o uso tecimento independente do tipo proporciona um menor valor da razão $\mathrm{R} / \mathrm{L}$, pois é possível aquecer mais nas laterais da poça de fusão aumentando sua capacidade de molhamento e proporcionando uma melhor distribuição da quantidade de material depositado sobre o material de base, o que resulta numa maior largura e num menor reforço para os cordões de solda, reduzindo assim os valores da razão $R / L$ [3,4]. No que diz respeito ao menor valor da razão $\mathrm{R} / \mathrm{L}$ apresentado pelo tecimento triangular em relação ao duplo oito, isto se deve ao fato de que durante a execução do deslocamento da tocha no tecimento triangular há a permanência do arco durante poucos instantes nas laterais da poça de fusão proporcionando assim um cordão mais largos e com menor reforço (menor R/L). 
Tabela 4 - Valores previstos e medidos das variáveis respostas para os ensaios d

\begin{tabular}{|c|c|c|c|c|c|c|}
\hline Ensaio & Critério & $\begin{array}{c}\text { Combinação } \\
\text { de fatores }\end{array}$ & (eta) & Previsto & Medido & $\begin{array}{c}\text { Intervalo } \\
\text { Admissível }\end{array}$ \\
\hline RC01 & $\mathrm{D}(\%)$ & 1221 & $-12,44$ & 4,2 & 5,7 & 2,9 a 6,0 \\
\hline RC02 & R/L & 3221 & 16,14 & 0,16 & 0,18 & 0,13 a 0,18 \\
\hline
\end{tabular}

A Vs também afetou significativamente esta variável resposta e o Nível $1(0,2 \mathrm{~m} / \mathrm{min})$ deste fator é indicado para se obter a menor razão $\mathrm{R} / \mathrm{L}$, o que demonstra que maiores $\mathrm{Vs}$ proporcionam maiores valores para a razão R/L. Resultado que se deve ao fato, de maiores Vs dificultarem uma melhor "molhabilidade" da peça ocasionando um reforço alto e uma largura pequena (maiores valores da razão R/L) [3].

\subsection{Ensaios de confirmação}

A combinação ótima dos níveis dos fatores de controle sugeridos pelo método Taguchi não estão contemplados nos ensaios da Tabela 1, sendo necessária a realização de ensaios de confirmação para verificar a veracidade de que essas combinações minimizam os valores das variáveis respostas.

A Tabela 4 mostra os valores previstos pelo tratamento estatístico do método Taguchi, os valores reais obtidos nas soldagens denominados nesta tabela de valores medidos e o intervalo de confiança para o valor previsto.

Como os valores da diluição e da razão $\mathrm{R} / \mathrm{L}$ obtidos nos ensaios de confirmação estão dentro do intervalo de confiança, conclui-se que o método Taguchi consegue avaliar com segurança a influência dos fatores de controle sobre as variáveis respostas escolhidas como critério de qualidade. Vale ressaltar que o valor de diluição obtido é adequado para as soldagens de revestimento, pois proporcionará baixo teor de ferro, o qual é exigido pela norma ISO 10423 adotada por indústrias do setor de petróleo e gás natural para as soldagens de revestimento em equipamentos com revestimentos metálicos [7].

Com relação a razão $\mathrm{R} / \mathrm{L}$ o baixo valor de 0,18 obtido indica um cordão de solda com baixa convexidade, capaz de minimizar as concentrações de tensão no pé do cordão de solda e evitar a ocorrência de defeitos como a falta de fusão, tornando-o adequado a soldagem de revestimentos.

\subsection{Análise de variância no método Taguchi para a matriz L9-2}

A Tabela 5 mostra o resultado de uma análise estatística para as soldagens referentes à matriz L9-2, na qual todos os fatores de controle afetaram significativamente todas as variáveis respostas utilizadas como critérios de qualidade (diluição, razão R/L). Nesta nova matriz L9 a tensão de referência e a velocidade de soldagem foram mantidas como fatores de controle, devido às suas influências na transferência metálica, no cálculo da energia de soldagem e na geometria do cordão de solda. Vale ressaltar que a posição empurrando para a técnica da tocha e o uso tecimento triangular, por minimizarem os dois critérios de qualidade (D e R/L) na matriz L9-1, foram utilizados em todos os ensaios da matriz L9-2.
Tabela 5 - Nível de significância dos fatores de controle sobre as variáveis respostas

\begin{tabular}{c|cc|}
\hline \multirow{2}{*}{ Fator de Controle } & \multicolumn{2}{|c}{ Nível de } \\
\cline { 2 - 3 } & Diluição & Razão R/L \\
\hline Liga & $\underline{0,000}$ & $\underline{0,000}$ \\
Gás & $\underline{0,000}$ & $\underline{0,000}$ \\
Vs (m/min) & $\underline{0,004}$ & $\underline{0,000}$ \\
Ur (V) & $\underline{0,000}$ & $\underline{0,001}$ \\
\hline
\end{tabular}

Com base na Tabela 5 verifica-se que todos os fatores de controle afetaram significativamente as duas variáveis respostas utilizadas como critérios de qualidade (diluição e razão R/L).

\subsection{Previsão da combinação ótima}

Assim como nos ensaios realizados na matriz L9-1 as variáveis respostas (diluição e razão $\mathrm{R} / \mathrm{L}$ ) foram avaliadas através de um tratamento estatístico do método Taguchi, onde essas variáveis são um problema de solução do tipo "quanto menor melhor. Assim as condições necessárias para obter os valores mínimos das variáveis respostas são representadas pelo maior valor de (eta).

\subsubsection{Análise da variável resposta Diluição (D)}

A Figura 8 mostra a influência dos fatores de controle sobre a diluição, a qual apresenta seu valor mínimo para a combinação de fatores de controle nos níveis "3 11 1", ou seja, a liga C-276 como material de adição, argônio puro como gás de proteção, velocidade de soldagem de $0,2 \mathrm{~m} / \mathrm{min}$ e uma tensão de referência de $20 \mathrm{~V}$.

Através de uma análise conjunta da Figura 8 e da Tabela 5 obtêm-se as seguintes informações da aplicação do método Taguchi com relação à influência dos fatores de controle sobre a diluição.

Com relação à liga o Taguchi aponta o Nível 3 (C-276) como a melhor opção para obter o valor mínimo da diluição, seguido pelo Nível 2 (686) e por fim o Nível 1 (625) que obteria os maiores valores. Acredita-se que este fato se deva à menor molhabilidade observada nos ensaios utilizando a liga C-276 em comparação com as outras ligas, o que faz com que o arco elétrico haja sobre o reforço excessivo do cordão de solda ao invés de atingir diretamente o metal de base, conseqüentemente reduzindo área fundida e com isso obtêm-se menores valores de diluição. Vale lembrar que neste e nos outros critérios de qualidade adotados a escolha da liga foi baseada apenas nas características geométricas, assim a escolha final da 
liga adequada para soldagens de revestimento dependerá da resistência à corrosão, resistência ao desgaste e das propriedades mecânicas destas ligas.

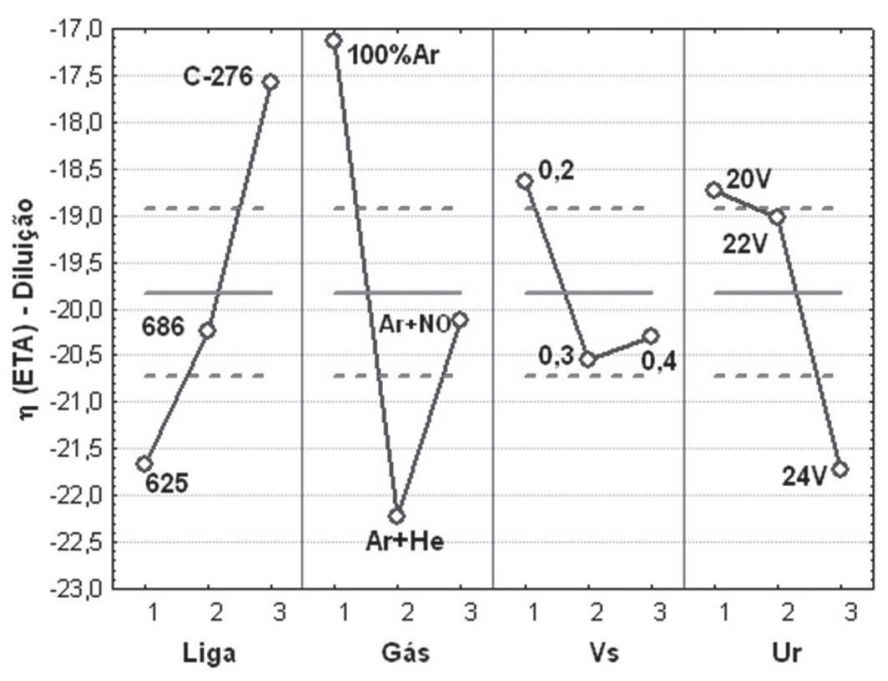

Figura 8 - Influência dos fatores de controle sobre a diluição.

Para o gás de proteção o Nível 1 (100\% Ar) é apontado como o nível capaz de obter o valor mínimo para a diluição. Isso se deve ao fato de que para a mistura $70 \% \mathrm{Ar}+30 \% \mathrm{He}$, contêm hélio, cujo alto potencial de ionização proporciona uma maior tensão do arco elétrico, o que, por sua vez, resulta em maiores aportes térmicos e, com isso, maiores diluições [3].

Com relação a Vs e Ur verificou-se que estes fatores de controle exercem influência significativa sobre a diluição. E demonstraram comportamentos idênticos aos apresentados e discutidos nos resultados obtidos para a matriz L9-1 onde o taguchi aponta o Nível 1 (Vs=0,2 m/min e Ur= $20 \mathrm{~V}$ ) para ambos os fatores, como sendo os níveis capazes de alcançar o menor valor tanto para este critério quanto para o critério seguinte, portanto a análise destes dois fatores não será abordada na razão $\mathrm{R} / \mathrm{L}$.

\subsubsection{Análise da variável resposta $R / L$}

A Figura 9 mostra a influencia dos fatores de controle sobre a razão $\mathrm{R} / \mathrm{L}$, cujo valor mínimo é dado para a combinação de fatores de controle nos níveis "1 213 ", ou seja, a liga 625 como material de adição, $70 \% \mathrm{Ar}+30 \%$ He como gás de proteção, velocidade de soldagem de $0,2 \mathrm{~m} / \mathrm{min}$ e uma tensão de referência de $24 \mathrm{~V}$.

Com base na Figura 9 e na Tabela 5 podemos extrair os seguir dados do uso do método Taguchi com relação à influência dos fatores de controle sobre a razão $\mathrm{R} / \mathrm{L}$.

A liga apresentou influência significativa sobre o valor da razão R/L, com o Nível 1 (625) sendo apontado como o nível capaz de minimizar o valor deste critério, obtendo o Nível 2 (686) valores intermediários e o Nível 3 (C-276) obteria os maiores valores. Este resultado, assim como no critério diluição, acredita-se estar associado à baixa molhabilidade dos cordões de solda obtidos com a liga C-276, acarretando em cordões de solda estreitos e com reforços excessivos, ou seja, elevados valores para a razão R/L. Já as ligas 625 e 686 apresentaram um comportamento similar para geometria de seus cordões, onde foram obtidos cordões largos e com pequeno reforço, ou seja, baixos valores de R/L.

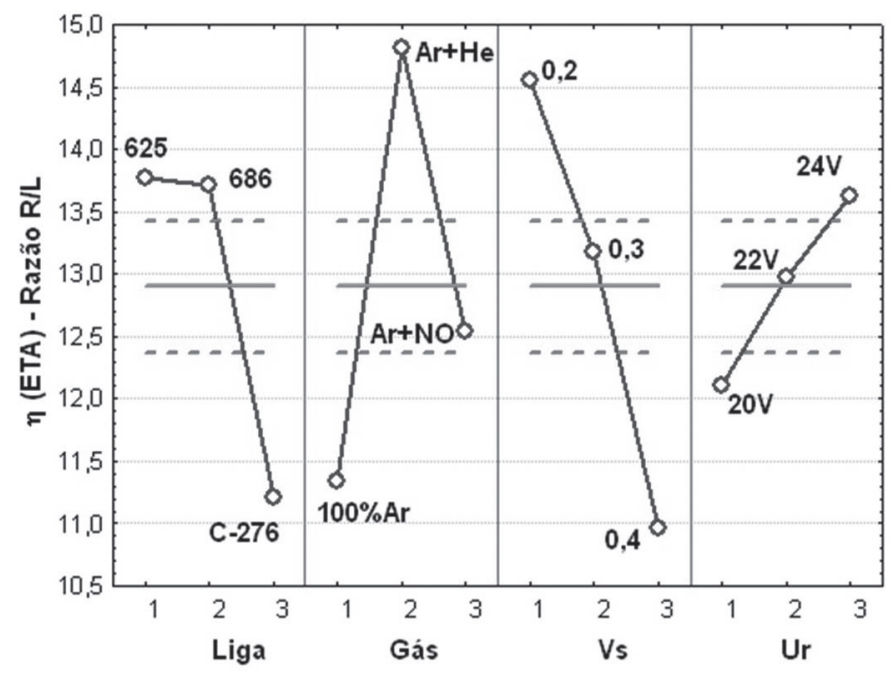

Figura 9 - Influência dos fatores de controle sobre a razão R/L.

O gás de proteção teve influência significativa sobre a razão R/L e o Nível $2(70 \% \mathrm{Ar}+30 \% \mathrm{He})$ deste fator de controle é apontado como nível que minimiza a razão $\mathrm{R} / \mathrm{L}$. Resultado condizente com a literatura, que atribui ao gás hélio, presente na mistura $70 \% \mathrm{Ar}+30 \% \mathrm{He}$, uma maior capacidade de trocar calor com a chapa a ser soldada, aumentando a fluidez da poça de fusão e melhorando a sua molhabilidade, o que resulta em cordões de solda mais largos (maior região fundida) e com baixos níveis de reforço quando comparados aos obtidos com o uso do argônio puro como gás de proteção [3].

\subsection{Ensaios de confirmação}

A combinação dos níveis dos fatores de controle sugeridos pelo método Taguchi não estão contemplados nos ensaios da Tabela 2, sendo necessária a realização de ensaios de confirmação para verificar a veracidade de que essas combinações minimizam as variáveis respostas.

A Tabela 6 mostra os valores previstos pelo tratamento estatístico do método Taguchi, os valores reais obtidos nas soldagens denominados nesta tabela de valores medidos e o intervalo admissível para o valor previsto.

Como os valores da diluição e da razão $\mathrm{R} / \mathrm{L}$ obtidos nos ensaios de confirmação estão dentro do intervalo de confiança calculado, conclui-se que o método Taguchi consegue avaliar com segurança as variáveis respostas escolhidas como critério de qualidade. Assim como nos resultados apresentado e discutidos para a matriz L9-1, os baixos valores obtidos para a diluição e para a razão R/L na matriz L9-2, tornam os parâmetros escolhidos pelo método Taguchi aptos a soldagem de revestimento. 
Tabela 6 - Valores previstos e medidos das variáveis respostas para os ensaios de

\begin{tabular}{|c|c|c|c|c|c|c|}
\hline Ensaio & Critério & $\begin{array}{c}\text { Combinação } \\
\text { de fatores }\end{array}$ & (eta) & Previsto & Medido & $\begin{array}{c}\text { Intervalo } \\
\text { Admissível }\end{array}$ \\
\hline $\mathrm{RC} 03$ & $\mathrm{D}(\%)$ & 3111 & $-12,61$ & 4,3 & 5,2 & 3,0 a 5,8 \\
\hline $\mathrm{RC} 04$ & $\mathrm{R} / \mathrm{L}$ & 1213 & 18,05 & 0,13 & 0,16 & 0,14 a 0,18 \\
\hline
\end{tabular}

\section{Conclusões}

Com base nos resultados experimentais apresentados neste trabalho foi possível concluir que:

- Os menores níveis para a tensão de referência e para a velocidade de soldagem ( $\mathrm{Ur}=20 \mathrm{~V}$ e $\mathrm{Vs}=0,2 \mathrm{~m} / \mathrm{min}$ ) resultaram nos menores valores de diluição.

- O uso do tecimento apesar de não afetar significativamente a diluição é um parâmetro essencial para a obtenção de baixos valores da razão $\mathrm{R} / \mathrm{L}$.

- A liga (material de adição) e o gás de proteção demonstraram ser parâmetros capazes de alterar significativamente as características geométricas dos cordões de solda. A liga C-276 e o gás $100 \%$ Ar obtiveram os menores valores de diluição, em contrapartida acarretaram nos maiores valores para a razão $\mathrm{R} / \mathrm{L}$.

- O uso do método Taguchi foi uma ferramenta estatística muito útil, pois permitiu com um reduzido número de ensaios avaliar e selecionar os parâmetros ótimos para obtenção das características geométricas desejadas para soldagem de revestimento.

\section{Agradecimentos}

Os autores gostariam de agradecer ao Laboratório de Engenharia de Soldagem, ao Laboratório de Caracterização de Materiais pertencentes a Universidade Federal do Ceará pelo suporte na realização dos experimentos, ao PRH-31( ANP) e ao CENPES (Petrobras) pelo suporte financeiro.

\section{Referências Bibliográficas}

[1] ROSS, P. J. Aplicações das Técnicas Taguchi na Engenharia da Qualidade São Paulo - SP: McGraw-Hill Ltda. 1991. 333 p.

[2] AWS. Welding Handbook - Welding Processes 9.ed. Miami: American Welding Society, v.2. 2004.

[3] SCOTTI, A. \& PONOMAREV, V. Soldagem MIG/MAG: melhor entendimento, melhor desempenho 1.ed. São Paulo: Artlibre. 2008. 284 p.

[4] MAGALHÃES, S. G. Avaliação do revestimento a base de liga de níquel em aço estrutural empregando o metal de adição ERNiCrMo-3 através da soldagem MIG/MAG. 2008. Dissertação. Universidade Federal do Ceará, Fortaleza, 2008.

[5] KEJELIN, N. Z.; BUSCHINELLI, A. J. A.; POPE, A. M. Influence of Welding Parameters on the Formation of Partially Diluted Zones of Dissimilar Metal Welds. Soldagem \& Inspeção, v.12, n.3, p.195 - 203, Jul./Set., 2007.

[6] GOMES, E. B. Análise do Comportamento da Soldagem por
Curto-Circuito aplicado ao Processo Eletrodo Tubular através da Metodologia Taguchi. 2006. Dissertação de Mestrado. Universidade Federal de Itajubá, Itajubá - MG,Maio, 2006. [7] ISO 10423. Petroleum and natural Gas Industries - Drilling and Production Equipment - Wellhead and Cristmans Tree Equipment. Switzerland: ISO 2003. 